\title{
Integrated analysis of photovoltaic system externalities in Brazil: public health expenditures, energy quality, architectural aspects and real estate value
}

\author{
Pedro Henrique Gonçalves Rigueira Pinheiro Castro ${ }^{1}$ (D), Delly Oliveira Filho ${ }^{1, *}$ (D), Olga Moraes Toledo ${ }^{2}$ (D), \\ Joyce Correna Carlo ${ }^{3}$ (D), and Antônia Sônia Alves Cardoso Diniz ${ }^{4}$ iD \\ 1 Agricultural Engineering Department, Federal University of Vicosa, Vicosa, Minas Gerais, Brazil \\ ${ }^{2}$ Electrotechnical Department, Federal Center for Technological Education of Minas Gerais, Leopoldina, Minas Gerais, Brazil \\ 3 Architecture and Urbanism Department, Federal University of Vicosa, Vicosa, Minas Gerais, Brazil \\ ${ }^{4}$ Mechanical Engineering Department, Pontifical Catholic University of Minas Gerais, Belo Horizonte, Minas Gerais, Brazil
}

Received: 13 December 2021 / Received in final form: 1 February 2022 / Accepted: 1 February 2022

\begin{abstract}
Photovoltaic solar energy systems is a renewable source that has raised great worldwide interest in recent decades. However, in Brazil still, the cost of photovoltaic (PV) systems is still high, and the current public policies are incipient. From 2014 to 2019, an average growth of $203 \%$ per year was observed in the installed PV power systems in Brazil. Such performance can also be justified by a greater understanding of externalities, i.e., external positive and negative impacts inherent to the generation of electric energy. The objective is to understand the economic effects of photovoltaic externalities from different perspectives. The following externalities were studied: air pollution; energy quality; construction element; thermal load and real estate valuation, and all of them were analyzed for the Brazilian scenario. The results indicated that the externality of air pollution, which has impacts on health, estimated from the society perspective, could be worth, at least, $4.12 \%$ of the price of the energy generated by PV systems. The losses avoided and the voltage profile, energy quality parameters, may account to $12.61 \%$ of the electricity price for utilities, and from the consumer perspective, the externality real estate value may be around $79.44 \%$ of the price of the electricity generated by photovoltaic systems. The results of this study indicate that the externalities were, for the most part, positive for PV electric energy generating systems. Thus, considering externalities, it is intended to further understand their relationship with the expansion of the distributed generation of electric energy with $\mathrm{PV}$ systems in Brazil.
\end{abstract}

\section{Implications and influences}

The motivation for carrying out this work is the need for greater understanding of the external factors arising from the installation of photovoltaic systems in Brazil. Understanding and mainly quantifying these externalities is of great relevance because it allows to understand the real economic potential and thus understand the great expansion of this technology in Brazil and mainly to stimulate growth, given that the quantified external impacts were mostly positive. Thus, the greatest contribution of this research is to quantify these external economic effects, significantly contributing to the feasibility of new projects that may not be viable in traditional economic analyses.

\footnotetext{
* e-mail: delly@ufv.br
}

\section{Introduction}

Population growth, combined with technological development, has increased the worldwide consumption of electricity. In such a scenario, meeting energy demand through non-renewable sources is a non-priority, in view of the increasing concern with environmental issues, especially the search for sustainable development [1]. The Brazilian electric matrix, despite being predominantly renewable, presented, from 2008 to 2017, a $45.7 \%$ growth in the non-renewable energy sources [2].

Photovoltaic systems (PV), a technology that has become one of the major trends in renewable energies, are an alternative for electric generation from renewable sources. Due to the significant growth in recent years and the high levels of investment involved, the PV market has become increasingly promising around the world [3]. 
Following the worldwide trend of using renewable sources of electric energy, although late, from 2014 to 2019, Brazil achieved an average growth of $203 \%$ per year in the installed capacity of PV systems [2].

The expansion of renewable sources can be an alternative to mitigate the dependence on new non-renewable sources in Brazil. Despite the current accelerated growth, in 2019, the capacity of photovoltaic systems totaled only $1 \%$ of the national energy matrix [2]. This fraction can be justified by the fact that the consolidated use of photovoltaic technology in Brazil took place only after the regulation of micro and mini-generation of energy in the country, which occurred at the end of 2012 [4].

In 2018, the installed capacity of PV systems in the world exceeded $505 \mathrm{GWp}$, which accounted for more than 33 times this figure in 2008, a growth equivalent to around $37.8 \%$ per year during that period [5]. Brazil has great potential for generating solar PV electricity. Such potential can be proven by the existence of large areas with direct radiation levels above $2000 \mathrm{kWh} / \mathrm{m}^{2} /$ year, especially in the Northeast Region [6]. In Brazil, advances in installed power have followed the global trend, but at a late stage, that is, the growth of PV systems started to be significant in 2012, and an installed power of $2.5 \mathrm{GWp}$ was achieved in 2019 [2].

At the beginning of the implementation of PV systems in Brazil, the acquisition of this technology involved initial investments higher than those required by other technologies. Currently, governments in different countries have promoted the installation of PV systems and are aware of the "mostly positive side effects" resulting from their use, which include: (i) increased employment rate and income and (ii) greater environmental sustainability [7]. These external effects, also known as side effects, are called externalities.

Externalities are positive or negative impacts, associated with a certain product or service, but generally not completely accounted for at the time of sale [8]. They are also defined as the attribution of economic value to impacts caused to the external environment [9]. Technicaleconomic assessments of electric energy generation options become trivial and widespread. Thus, the inclusion of externalities should lead to significant changes in feasibility among the different investment options. There are examples of the consideration of externalities and their effects on countless sectors, such as in the feasibility analysis of LED lamps and in the disposal of solid waste [10-12].

The externalities inherent to the generation of electric energy by thermoelectric plants powered by fossil fuels are negative. The impacts of these polluting sources cause several environmental problems that affect the quality of life of human beings. External costs reflect the damage caused by these emissions in the form of externality and, in this case, it is completely negative [13]. Therefore, the traditional economic feasibility analysis may be inaccurate. Besides, the consideration of externalities allows for a more representative economic analysis that includes environmental impacts, which have currently become an increasing concern worldwide.
The externalities related to environmental factors was considered in an integrated energy system research and demonstrated that the PV electrical energy has economic advantages over thermal energy [14]. The qualitative assessment of externalities is also a common point in recent studies [15], not the quantitative ones. In addition, externalities, when not quantified, can negatively influence feasibility studies of PV systems as opposed to fossil sources [16]. Thus, it is necessary to seek a methodology that allows to quantify the economic effect of externalities. This assessment of a set of externalities of PV systems is not yet found in the literature.

It is believed that the economic consideration of externalities arising from PV technology may be one of the factors that justify the recent growth of this technology in Brazil, despite a strong economic crisis that started in 2014, whose effects can still be felt to the present day [17]. In spite of the economic crisis, the installed power of PV systems increased in the country from 2014 to 2018 [2]. Thus, assessing the real economic effect of a set of externalities can be fundamental for understanding and maintaining investments in PV systems implementation in Brazil.

The consideration of the economic value of externalities, that is, pricing a given externality, directly involves the perspective or the subject, i.e., for the case of PV systems, one can consider, for example, the perspective of the owner of the PV system, or the electric utility or society. Thus, the consideration of an externality involves the perspective from which the study is proposed to be carried out, since an externality may assume a different value - depending on the approach or perspective. The analysis of externalities can be developed for each situation or perspective involved.

This research has as its objective to propose a new methodology to equate the value of externalities from the installation and use of solar PV systems for the generation of electric energy and understand the economic effects of externalities, in the context of the players involved i.e. whether from consumers, utilities and society. The relevance of this study isimportance of understanding the growth dynamics of photovoltaic implementation in Brazil from different perspectives.

\section{Materials and methods}

This research was carried out at the Energy Laboratory of the Federal University of Vicosa using available data from literature. The related externalities in this work were defined as the impacts arising from the use of electric energy generated by PV systems. The value of the selected externalities was assessed for the Brazilian scenario, as currently as possible.

Externalities related to: (i) air pollution, (ii) energy quality, (iii) construction element, (iv) thermal load and (v) real estate valuation were analyzed for the Brazilian scenario. For this purpose, data referring to PV systems were evaluated, considering the installation directly in consumer units. 
For the purpose of calculating and comparing the value of externalities, the average cost of electricity for the Brazilian consumers was verified, in 2018. Considering that the energy generated by PV systems can assume the same price, the value of the externalities of these systems was calculated based on the energy price, i.e., the value of each externality was calculated as a percent of the MWh price of the Brazilian market.

\subsection{Air pollution}

The methodology of this section addresses the perspective of society. This externality was quantified considering that greater participation of the energy generated by PV systems in the current Brazilian scenario may reduce public health spending and atmospheric emissions. Also, the value of the $\mathrm{tCO}_{2}$ eq that is no longer emitted can generate carbon credits, and so the air pollution externality is obtained by adding the two listed sub externalities, i.e., emissions avoided and avoided expenses on public health, which were quantified. It was also considered that increased participation of energy from PV systems can reduce emissions from the current Brazilian matrix. The value of this externality was quantified to increase the electric energy from PV systems up to $10 \%$ of the total electricity generated in 2018 in Brazil.

To calculate the economic value of the sub externality emissions avoided by the generation of energy by PV systems, the ratio between emissions in $\mathrm{tCO}_{2}$ eq and the total electricity generated in Brazil in 2018 was initially considered; this quantity resulted in $0.088 \mathrm{tCO}_{2} \mathrm{eq} / \mathrm{MWh}[2]$. Equation (1) was used to calculate the emissions in $\mathrm{tCO}_{2} \mathrm{eq}$ per MWh of the Brazilian electrical matrix after the addition of PV systems, since it was considered that the emissions of this matrix will be reduced by an increased participation of the PV systems in the Brazilian Matrix,

$$
T_{p v}=\frac{T_{t} E_{g}}{E_{g}+E_{p v}}
$$

where $T_{p v}=$ emissions from the Brazilian electrical matrix, which are used to install PV systems, in $\mathrm{tCO}_{2} \mathrm{eq} / \mathrm{MWh}$; $T_{t}=$ emissions from the Brazilian electrical matrix, in $\mathrm{tCO}_{2} \mathrm{eq} / \mathrm{MWh} ; E_{g}=$ current electricity energy generated in Brazil, in MWh/year; and $E_{p v}=$ electrical energy generated by PV systems, in MWh/year.

Equation (2) was used to calculate the sub externality of emissions avoided in $\mathrm{tCO}_{2}$ eq in function of the quantity of MWh generated by PV systems. This equation estimates the value avoided of emissions based on the emissions from the Brazilian electrical matrix, which are used to install PV systems, carbon credit quotation and electricity cost,

$$
V_{e}=\frac{T_{p v} C_{c}}{E} 100
$$

where $V_{e}=$ sub externality value emissions avoided, in percent of the electrical energy rate; $C_{c}=$ carbon credit quotation, in $\mathrm{US} \$ / \mathrm{tCO}_{2}$ eq; and $E=$ electricity cost, in US\$/MWh.
The sub externality of avoided expenses on public health was calculated considering that, due to reduced pollutant emissions, less investment in health treatment is required. To price this sub externality, results from [18] were used, according to which the cost estimates of externalities linked to environmental and health aspects range between $6.0 \%$ and $82.9 \%$ of the MWh price. [18] estimated, by a weighted average of the Brazilian generation mix, that the effect of pollution on the Brazilian population generates an increase in public health expenses that accounts for about $3.8 \%$ of the cost per MWh generated. Equation (3) is used to quantify the impact of the insertion of PV systems in the current Brazilian electrical system, taking into account that emissions in $\mathrm{tCO}_{2}$ eq are directly proportional to public health costs. This consideration was simulated by adding electric energy from PV systems until reaching $10 \%$ of the total national consumption in 2018,

$$
V_{a e}=\frac{T_{t} E_{g}}{T_{t}\left(E_{g}+E_{p v}\right)} P_{h}
$$

where $V_{a e}=$ value of externality avoided expenses on public health, in percent of the electrical energy rate; $P_{h}=$ public health expenditure of the current energy matrix, in percent of the electrical energy rate; and $V_{e l}=$ value energy losses avoided in the distribution of electricity with the use of $\mathrm{PV}$, as a percent of the electrical energy rate.

\subsection{Energy quality}

For the energy quality, three sub-externalities were considered: (i) energy losses avoided in the distribution, (ii) voltage profile and (iii) loss due to the unsupplied energy. The pricing of this externality from two perspectives is justified, as some effects may be more meaningful both for the energy utility, such as reduced losses and voltage profile, and for the consumer, such as reduced periods of non-supply of electrical energy.

The losses avoided in the Brazilian power system due to the distributed PV system insertion on grid were estimated. It is known that technical and non-technical losses account for around $7.50 \%$ and $6.60 \%$, respectively, for Brazil, for the year 2018 [19]. The estimated energy losses in PV systems were around 1.50\% [20]. This estimate considers losses at the connection point and in the cables of the PV systems for distributed energy generation. Equation (4) estimates the percentage avoided with losses in energy distribution when PV systems were used. It was considered that non-technical losses do not depend on the implementation of PV systems, while the technical losses are directly affected by the implementation of PV systems,

$$
V_{e l}=\left(\frac{T_{l}\left(E_{g}-E_{p v}\right)}{E_{g}}+N_{t l}-L_{p v}\right) 100
$$

where $T_{l}=$ technical losses, dimensionless; $N_{t l}=$ non-technical losses, dimensionless; and $L_{p v}=$ losses of PV systems, dimensionless. 
Electricity loss reduction was considered an economic gain. In this line, the result of equation (4) assumed a value corresponding to the sub externality energy losses avoided in the distribution by the insertion of the PV system. As the losses depend on the amount of electric energy from PV systems, this sub externality value was estimated considering an insertion range for new PV systems up to about $10 \%$ of the total electricity generated in 2018 in Brazil.

The sub externality voltage profile was calculated considering that the implementation of PV systems generally improves the voltage profile [21-23]. It was considered that a PV on grid system installed in a way connected to the electrical system can avoid the payment of possible compensation, by the utility to the consumers, related to the non-compliance with the voltage profile levels avoiding the installation of control system units.

In this research, it was considered that the value of this sub externality can be estimated as a function of the total compensation paid in 2018 for non-compliance with the voltage profile standards in relation to the total electrical energy supplied in the period [24].

The total energy generated in Brazil in 2018 was 636.4 TWh [2]. Equation (5) was used to estimate the value of the voltage profile externality as a function of the costs that could be avoided by paying compensation from the perspective of the energy utility. Costs were given by the ratio between the total economic compensation and the total energy rate supplied to final consumers,

$$
V_{v p}=\frac{\sum C_{p}}{E_{g}\left(1-T_{l}-N_{t l}\right) E} 100
$$

where $V_{v p}=$ value of the value voltage profile, in percent of the electrical energy rate; and $C_{p}=$ compensation paid by the electric utilities for the voltage profile externality, in US\$/year.

The sub externality loss due to the unsupplied energy, that is, the damage caused by the fact that energy was not supplied by the utilities to the consumers. In that case, it was considered that intentional islanding was settled in order to supply energy in case of an interruption. The calculation of the cost of not supplied energy loss was based on the average value of lost load found in the international literature, as presented in Table 1.

Average data were used to allow the calculation of the sub externality value. The average period in which Brazilian consumers were without electricity in 2018 was $12.85 \mathrm{~h}$ [33]. In the same year, the national energy consumption for the commercial, residential and industrial sectors were around 90.7, 136.2 and $200.9 \mathrm{GWh} /$ year, respectively [2]. It was possible to calculate, using equation (6), the value of the sub externality loss due to the unsupplied energy. First, it was estimated the value of the unsupplied energy, according to equation (6), for the commercial, residential and industrial sectors, as the average of the values shown in Table 1.

$$
V_{u e}=\frac{\left(E_{c} R_{c}+E_{r} R_{r}+E_{i} R_{i}\right) A_{i}}{\left(E_{c}+E_{r}+E_{i}\right) 8760} 100
$$

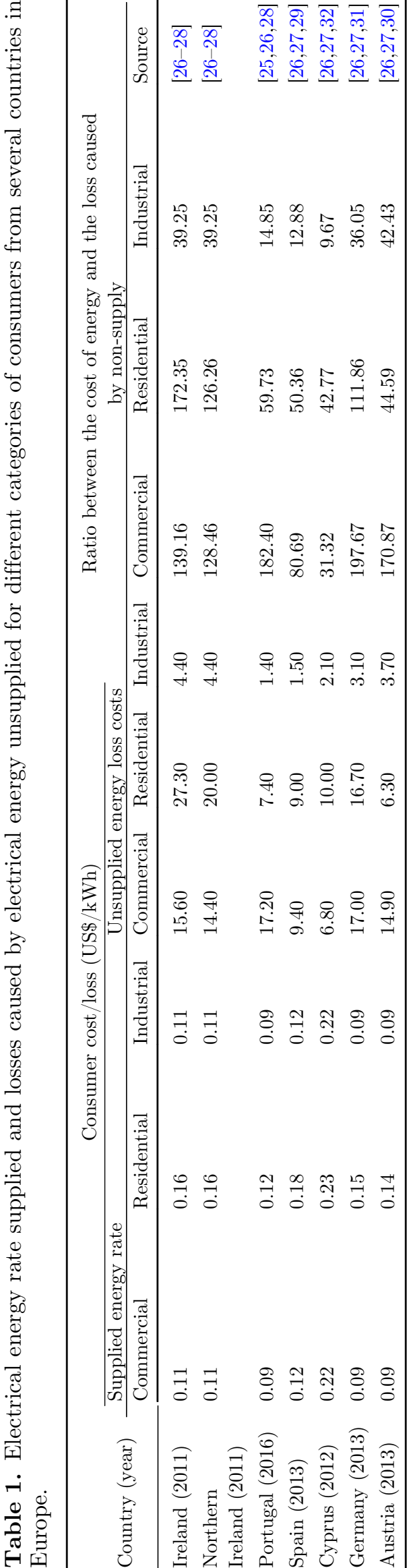


where $V_{u e}=$ value of sub externality loss due to the unsupplied energy, as a percent of the electrical energy rate of electricity; $R_{c}=$ ratio between the cost of energy and the loss for the commercial sector, dimensionless; $E_{c}=$ energy consumption in 2018 for the commercial sector, in MWh/year; $R_{r}=$ ratio between the cost of energy and the loss for the residential sector, dimensionless; $E_{r}=$ energy consumption in 2018 for the residential sector, in MWh/year; $R_{i}=$ ratio between the cost of energy and the loss for the industrial sector, dimensionless; and $E_{i}=$ energy consumption in 2018 for the industrial, in $\mathrm{MWh} /$ year; $A_{i}=$ average interruption time, hours per year.

\subsection{Constructive element}

The externality constructive element is defined by the possible use of photovoltaic panels as constructive elements, for example: replacement of traditional tiles by PV panels, as these are waterproof structures. The externality constructive element was economically evaluated from the perspective of consumers who had opted for the installation of PV systems in their building roofs that usually have enough area and often without shading. In order to enable the pricing of this externality, market prices of five types of tiles were researched to compare the costs in relation to the coverage with PV panels. The average cost obtained for the tiles was $10.04 \mathrm{US} \$ / \mathrm{m}^{2}$.

Data from a conventional $350 \mathrm{Wp}$ PV panel with $17.64 \%$ plate efficiency were selected, with an area of 1984 $\mathrm{m}^{2}$, an expected life of 25 years and a cost of US\$ 166.43 [34]. To evaluate the generation potential of this panel, the average direct radiation in Brazil was considered to be $2 \mathrm{MWh} / \mathrm{m}^{2}$ year, and the overall performance of the panels' $\mathrm{DC}$ connection, the frequency inverter and the $\mathrm{AC}$ connection of these systems to be equal to $94.8 \%$ [35]. Taking into account that the loss of efficiency of the panel is linear throughout its useful life, an average efficiency of $90 \%$ was considered during the entire period of operation, in order to represent the loss of performance in that time [36].

The value for this externality was calculated using Equation (7).

$$
V_{c e}=\frac{C_{t}}{A_{d r} A_{e f} E \eta_{p v} \eta_{c} P} 100
$$

where $V_{c e}=$ value of externality constructive element, as a percent of the electrical energy rate of electricity; $C_{t}=$ average cost of conventional tiles, in US $\$ / \mathrm{m}^{2} ; A_{d r}=$ average direct radiation, in $\mathrm{MWh} / \mathrm{m}^{2} /$ year; $A_{e f}=$ average efficiency of a PV panel in its useful life, dimensionless; $\eta_{\mathrm{pv}}=$ performance PV panel, dimensionless; $\eta_{c}=$ performance conversion from DC to $\mathrm{AC}$, dimensionless; and $P=$ period of operation of the PV system, in years.

It was assumed that the roof structure, as well as the rest of the building, can be maintained, considering the replacement of conventional tiles with PV panels.

\subsection{Thermal load}

The evaluation of the thermal load essentially depends on the building structure, the material used and the site location. Thus, to quantify the thermal load from the installation of PV panels, it is initially necessary to determine how they will be installed; whether to be placed on existing roofs or directly on the surface to be covered. Given the wide range of positioning of the panels, determining the thermal load becomes necessary for each case.

As this externality directly impacts energy consumption, the effects of the thermal load inside the building itself were evaluated, that is, the externality was quantified from the consumer's perspective. To evaluate this externality in the most comprehensive way possible, a representative model of single-family residential building typical of the Brazilian scenario was selected.

The Methodology of [37] was used for thermal simulations in the EnergyPlus and SketchUp software with the Legacy Open Studio plugin, for a single-family residential model. The approach of [18] was adopted to assess the effects of temperature inside the building. Xavier simulated two situations: (i) conventional roof tiles and (ii) considered replacing the tiles with PV panels. The cases made it possible to analyze the effect caused by the replacement of conventional tiles by PV systems. The simulations were carried out in the Brazilian cities of Bento Goncalves, RS (latitude $29^{\circ} 10^{\prime \prime} 17^{\prime} \mathrm{S}$ ), Vicosa, MG (latitude $20^{\circ} 45^{\prime} 14^{\prime \prime} \mathrm{S}$ ) and Palmas, TO (latitude $10^{\circ} 12^{\prime} 46^{\prime \prime} \mathrm{S}$ ).

\subsection{Real estate valuation}

The real estate valuation can be obtained by the aggregation PV systems in the property. A traditional methodology to quantify the value of this externality is the analysis of historical commercial transactions of properties with PV systems, in order to determine the valuation of these properties due to the use of this technology.

The use of PV systems in homes is a relatively recent event in Brazil, since the installation of distributed generation systems integrated into the electrical system started only in 2012 [4] and established the necessary conditions for the installation of micro and mini-generation PV systems.

Because the data of commercial transactions in real estate in Brazil that have PV systems were not available thus, data from [38] was adopted, which estimated, through an interview, the willingness of eventual consumers to pay more for properties that have PV systems for electricity generation.

Reference [38] determined the minimum number of people to participate in order to achieve $90 \%$ reliability, with a sample error estimated at about $\pm 5 \%$. The result indicated that $73.7 \%$ of them would purchase property with a PV system and declared that they would be willing to pay some extra capital for a building with PV generation system, that is, the majority (33.3\%) would pay $5 \%$ to $10 \%$ above the price of a real estate.

The pricing of Brazilian real estate was estimated using the results of the [38] methodology and the consideration of the average price per square meter for sale in Brazil, according to [39], calculated as US\$ $1590.13 / \mathrm{m}^{2}$. 
The average residential energy consumption in 2018 was estimated considering that there were around 71 million residential properties in the country and a total consumption of 136.2 TWh of electric energy [2].

According to [37], the average size of a single dwelling property in Brazil is around $60 \mathrm{~m}^{2}$, in this case, for a family with 2.4 people, on average. Equation (8) was used to calculate the value of the externality real estate valuation of an average size property. The calculation was carried out using the ratio between the average appreciation of the real estate and the avoided costs with electricity due to the use of a PV system for a period of 25 years.

$$
V_{r s}=\frac{P_{r s} P_{v} A}{\left(\frac{E_{r}}{N_{r}}-M_{e}\right) E P}
$$

where $V_{r s}=$ value of externality real estate valuation, as a percent of the electrical energy rate of electricity; $P_{r s}=$ average home dwellings prices in Brazilin 2018, US $\$ / \mathrm{m}^{2} ; P_{v}=$ residential property valuation with PV system, in percent; $N_{r}=$ number of residential properties in Brazil in 2018, dimensionless; $A=$ residential property area, $\mathrm{m}^{2}$; and $M_{e}=$ minimum energy consumption of the utility, MWh/year.

\section{Results and discussion}

In Brazil, the externalities and their sub-externalities addressed in this research for PV systems were valued considering the electricity price used in the calculations, including the taxes, i.e., an average energy rate of 178.52 US\$ / MWh in 2018 [40].

\subsection{Air pollution}

For the air pollution externality, two sub-externalities were considered, from the perspective of society: (i) avoided emissions and (ii) avoided spending on public health. For these two sub-externalities, the dynamic effect of inserting the distributed generation was gradually considered up to the value corresponding to $10 \%$ of the electricity consumed in 2018 in Brazil, that is, from $1 \mathrm{MWh}$ to $63.4 \mathrm{TWh}$ PV. In this simulation, the emissions from the electrical matrix ranged from 0.088 to $0.080 \mathrm{tCO}_{2} \mathrm{eq} / \mathrm{MWh}$.

The value of the first sub externality, avoided emissions, was evaluated by considering the carbon credit quotation at $\$ 6.49 / \mathrm{tCO}_{2} \mathrm{eq}$ and using equation (2), it was found that the value of the emissions avoided corresponded to about $0.32 \%$ of the value of MWh, which reached $0.29 \%$.

If electricity matrix emission data from USA, European Union and China were considered, this externality would have its value increased by $365 \%, 288 \%$ and $583 \%$, respectively [2]. It is noteworthy that the value obtained for Brazil is possibly lower than that of the places mentioned, since the Brazilian electrical matrix is predominantly clean and renewable, that is around $83 \%$. If the potential for substitution by sources of electric energy, such as thermal power plants fueled by fossil fuels, were considered, a greater figure would possibly be observed for this sub externality.
The value of the second sub externality, avoided expenses on public health, was calculated from equation (3), resulting in this sub externality ranging from $3.80 \%$ to $3.46 \%$ of the energy rate. The highest percent was the increase of $1 \mathrm{MWh}$ of PV systems, considering the electric matrix of 2018, since the lowest percent was obtained when considering the addition of $10 \%$ of the PV energy consumed in that year. Thus, the marginal value results in higher savings, which could be a wise principle to propose as a public policy. If the calculation considered data from regions close to the electricity generation facilities using fossil fuels were adopted, the value of this sub externality could be much higher, since these regions tend to have higher levels of pollutants in the atmosphere.

By adding the two sub-externalities reported, it is possible to estimate the value of the externality air pollution. The values range from $4.12 \%$ to $3.75 \%$ of the energy price generated by the PV systems. The decreases correspond to a greater insertion of PV systems, as they contribute to the reduction of GHG emissions.

The interest in the analysis of some factors that can directly affect the economic value of the externality air pollution is justified, since: (i) the price of Brazilian electricity is higher than that of most countries; and (ii) the cost of carbon equivalent credit is below the real social impact of carbon, mainly due to the non-renewal of the Kyoto Protocol, which addressed Clean Development Mechanism (CDM) and carbon credits that expired in 2012 [41]; These factors most likely increase the value of this externality in Brazil. A 10-fold increase in the price of carbon credit and public health expenditure due to pollutant emissions from the national electricity matrix would result, respectively, in externality air pollution values equal to $7.00 \%$ and $38.32 \%$ of the price of the $\mathrm{MWh}$ generated by $\mathrm{PV}$ systems, respectively, as shown in Figure 1.

In Figure 1, it is evident that the increased price of carbon credits may further increase the value of the air pollution externality. The consideration of not only the social expenses and costs of health treatment, but also the willingness of individuals to pay more in exchange for better health, could also value the externality of air pollution, since the results could reach higher values than those mentioned here. As an example, in studies conducted in the cities of Sao Paulo, Brazil; Mexico City, Mexico and Santiago, Chile, it was concluded that individuals are willing to pay, on average, eight times more than average government spending on public health to have better quality of life [42].

The calculation methodology proposed in this research to estimate the value of the externality of air pollution considers only emissions from the generation of electricity, that is, from generating plants already built and operating under present conditions. Finally, the sub externality related to avoided emissions can be broken down into others, linked to environmental factors and sustainable development. This could be further studied in other research works. 


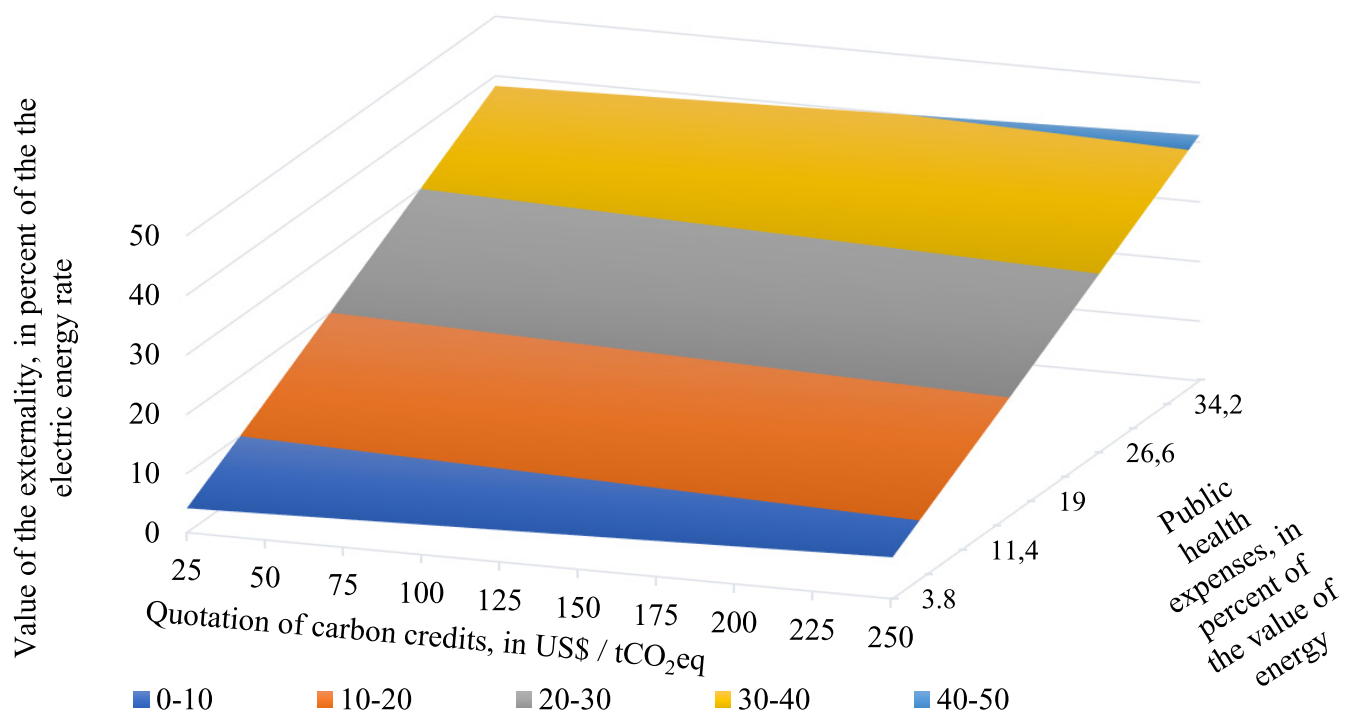

Fig. 1. Value of the air pollution externality as a function of carbon credit quotation and public health expenses, for the Brazilian 2018 energy matrix.

\subsection{Energy quality}

For the externality energy quality, the following economic values of sub externalities were considered: (i) energy losses avoided in the distribution utility, (ii) voltage profile and (iii) loss due to the unsupplied energy for the customers. For the first two sub externalities, the results were found considering the perspective of the electric utility. For the third sub externality, the results were found considering the perspective of the consumer. This methodology was adopted, since the energy not supplied causes greater impacts on the consumer in relation to the distribution utility, since the economic value referring to the loss of the electricity not supplied is much smaller, that is almost 200 times than the value of overall losses to the customer due to the not supplied energy, as shown on Table 1.

However, the unsupplied energy causes significant losses to the electric utilities in the form of fines regulated by the State Agency, such as the worsening of the reliability indices, an increased number of interruptions, the maximum interruption period and the total energy unsupplied. The generation distributed by PV systems could improve the energy quality, not only for the voltage profile, but also the above indices. Therefore, the implementation of PV systems would also be a positive sub externality for utilities. Studies should be conducted to detail the relationship between the distributed PV generation and each of these indices.

The value of the sub externality energy losses avoided in the distribution system was estimated by equation (4). The results indicate that this value ranged from $12.60 \%$ to $11.85 \%$ of the energy rate. The highest figure was obtained considering a marginal increase of $1 \mathrm{MWh}$ of electric energy from PV systems as the electric energy consumed in Brazil in 2018. The lowest percent was obtained considering the same condition, but with the additional PV energy equal to $10 \%$ of the national value. It is noteworthy that reduced externality value is logic due to the increased energy from distributed generation PV systems. This is because, since the more PV energy is provided by distributed generation systems, the less the main power plants and transmission lines are loaded.

For the second sub externality, voltage profile, its value was estimated using equation (5). This sub externality was evaluated as having less than $0.01 \%$ of the energy rate. This figure is lower than that of the other sub externalities, which were paid by the utilities in Brazil in the year 2018 and which could be avoided if investments were made in generation distributed at critical points in the system.

The last sub externality, unsupplied energy loss value, had its value estimated by equation (6), according to the consumer's perspective. The result of this equation indicates that the sub externality can reach about $10.10 \%$ of the energy rate, by considering the data of the customer losses due to the energy not supplied used. According to the data in Table 1, this loss approaches 133 times the value of the energy supplied, which is $178.52 \mathrm{US} \$ / \mathrm{MWh}$, and accounts for a loss that can reach $23,743.78 \mathrm{US} \$ / \mathrm{MWh}$, on average. In that case, the PV systems and their load may need intentional islanding, to avoid the losses caused by the fault or contingency, but this procedure remains prohibited by Brazilian legislation. However, the value of this sub externality, even if based on data from Europe adapted to the Brazilian context, evidence that Brazil should propose regulations on this matter.

The externality energy quality given by the results of these mentioned sub externalities reached around 12.61 and $10.10 \%$ of the energy rate in the perspectives of utility and customers, respectively. The value of this externality can be even higher if other additional energy quality parameters are to be considered, such as total harmonic distortion, THD and the topology - i.e. radial or ring or mist - due to the installation of distributed generation with PV systems. 
The values found for the sub externalities voltage profile and loss due to the unsupplied energy for the customers may assume much higher values if specific situations are considered. These situations can be for analyzes involving consumers located at critical points in the system, where the number of shortages and their quantity is higher than the average values considered in the study. Therefore, the reliability indices of the specific location on the grid where a certain consumer is installed can result in much higher values than those obtained with average data.

\subsection{Constructive element}

The externality constructive element was calculated using equation (7), considering the perspective of the consumers who install PV systems directly on their property. The result of equation (7) indicated that, when PV panels are installed to replace conventional tiles, this externality was evaluated at around $0.75 \%$ of the price of the electricity generated by these systems over 25 years.

The value of this externality was found based on the average price of tiles, considering the direct replacement by PV panels. Any changes to the roof structure were not considered, but they could further favor this externality. The methodology proposed for this externality considers the installation of PV systems in places where new roofs have not yet been built. When the roof is already built, the externality of the construction element may have a value lower than that calculated, since the roof material has already been depreciated. However, there may be other gains that will further the externality value, for example: (i) increased useful life of the existing roof, if it is covered with PV panels; (ii) use for shading windows or gardens and parking lots; and (iii) use of PV generators in blind facades.

\subsection{Thermal load}

The externality thermal load was evaluated according to Xavier (2015) simulation results. The results obtained consider the $0.10 \mathrm{~m}$-thick concrete roof slab. According to this author, the use of PV panels as a covering element in replacement of conventional tiles changed the average daily interior temperatures, and the temperature rise reached a maximum of $0.60{ }^{\circ} \mathrm{C}$ in some days of the year in the different simulated regions. It can be considered, for the Brazilian case, that the external thermal load does not generate significant changes. This temperature difference may be insufficient to cause discomfort, in constructions with a concrete slab and consequently higher energy consumption for AC.

However, if the same replacement of tiles by PV panels is performed in a house without a concrete slab, the results may be different, as this building element may provide thermal insulation. In addition, the simulation results of [18] were based on average daily data. In other words, situations may occur throughout the day, in which the temperature differences between the two simulated cases are different from the daily average. Hourly simulations may provide more accurate results of this externality.
Under certain conditions, the results of the use of PV systems may cool the room if the panels are installed aiming to avoid direct solar radiation $[43,44]$.

\subsection{Real estate valuation}

The real estate valuation externality was estimated as a valuation of the property where the PV system was installed. According to [38], the minimum valuation for a property with a PV system was $5.00 \%$ of its real estate price. The result of equation (8) indicates that this externality may be worth around $55.72 \%$ of the price of the electricity generated in its useful life, in a single dwelling property with average size, in Brazil [37].

Some international studies have confirmed the real estate valuation resulting from the installation of PV systems. In Arizona, U.S. there was an appreciation of around $17.00 \%$ of residential properties with PV systems, a figure even higher than that used in this study [45]. If this amount were used for Brazil, the externality would have reached the value of around $189.44 \%$ of the energy generated by PV systems.

\subsection{Overall PV system externality evaluation}

The economic values of the externalities addressed were grouped and added according to the perspectives considered in the methodology. Table 2 presents the value found for each of the externalities as a percent of the energy rate generated by the PV systems. The economic values of the externalities exhibited in Table 2 correspond to the marginal values.

Table 2 shows that the sub externality of avoided expenses on public health was the most valuable from society's perspective, with $3.80 \%$ of the energy generated by the PV systems. As for the utilities, the sub externality losses avoided in the distribution was the most significant and corresponded to $12.60 \%$ of the price of electricity generated by PV systems. For the consumers, the greatest value comes from the externality real estate valuation, corresponding to $55.72 \%$ of the price of electricity generated by the PV systems.

Thus, it highlights the relevance of considering externalities in the feasibility analysis of PV systems, since these systems offer much more than only electricity, as demonstrated.

This is one of the first attempts to systematize an assessment of the value of a set of externalities in relation to the value of the core activity, which in this case is the generation of electricity through on grid PV systems.

The corresponding values in Table 2 serve as the basis for carrying out an economic analysis of the useful life, as each $\mathrm{kWp}$ of photovoltaic installation provides financial returns not only from electricity generation, but also from externalities and contributes to a significant increase in attractiveness, especially to consumers.

In addition to being based on the value of energy, the impacts of externalities can be calculated differently, as a percentage of the initial investment, which allows an alternative view. This could assist in the design of public 
Table 2. Marginal value of externalities for different perspectives in Brazil, 2018.

\begin{tabular}{|c|c|c|c|c|}
\hline \multirow{2}{*}{ Externalities } & \multirow{2}{*}{ Sub externalities } & \multicolumn{3}{|c|}{$\begin{array}{c}\text { Marginal value of externality for different perspectives } \\
(\% \text { of the photovoltaic energy value) }\end{array}$} \\
\hline & & Consumers & Utilities & Society \\
\hline \multirow[t]{2}{*}{ Air pollution } & Emissions avoided & - & - & 0.32 \\
\hline & $\begin{array}{l}\text { Avoided expenses on } \\
\text { public health }\end{array}$ & - & - & 3.80 \\
\hline \multirow[t]{3}{*}{ Energy quality } & $\begin{array}{l}\text { Energy losses avoided } \\
\text { in the distribution }\end{array}$ & - & 12.60 & - \\
\hline & Voltage profile & - & 0.01 & - \\
\hline & $\begin{array}{l}\text { Loss due to the } \\
\text { unsupplied energy }\end{array}$ & 10.10 & - & - \\
\hline \multicolumn{2}{|c|}{ Construction element } & 0.75 & - & - \\
\hline \multicolumn{2}{|c|}{ Thermal load } & 0.00 & - & - \\
\hline \multicolumn{2}{|c|}{ Real estate valuation } & 55.72 & - & - \\
\hline \multicolumn{2}{|l|}{ Total } & 66.57 & 12.61 & 4.12 \\
\hline
\end{tabular}

policies that promoted photovoltaic systems and favored initial investment in energy generated by the photovoltaic system.

Other externalities should be considered in further studies, for example: (i) those arising from life cycle analysis, such as energy, water and material footprints; (ii) the use as backup energy; (iii) energy independence; and (iv) postponement of investment in electricity distribution networks.

\section{Conclusion}

The present work demonstrated that the economic value of externalities related to the renewable energy source photovoltaic system is significant in terms of its marginal values, compared to the value of the electric energy generated by these systems. From the perspective of consumers, reaching more than $66 \%$ of the value of energy generated. From the perspective of utilities, more than $12 \%$ and society, PV systems represent about $4 \%$ of the generated $\mathrm{kWh}$ value, which certainly changes the economic feasibility in these evaluation perspectives. Thus, the inclusion of externalities in the economic analysis for the implementation of new installations of PV systems is relevant and enables the further understanding of hidden economic issues.

Some externalities may shadow each other, which means that they may have similar effects in some cases and/or perspectives. It should be noted that the results provided relate to the average values and, therefore, may not accurately, or unequivocally, express the externalities referring to specific cases. Thus, economic studies on the feasibility of the installation of systems should always consider all the specifics of each situation. The evaluation carried out in this study considered average data and pointed out that the Real estate valuation externality can assume a greater value, representing about $56 \%$ of the energy generated by the PV system, in contrast to the thermal load externality was null. Thus, as highlighted, a punctual evaluation can present different results from these, due to the particularities of each situation.

The results of this study indicate that the externalities were, for the most part, positive for PV electric energy generating systems. Thus, with the consideration of externalities, it is intended to understand and enable the expansion, in Brazil, of electric energy generation technologies with renewable sources. Among the possible demands, we highlight that of providing greater attractiveness to the consumer, which may justify new public policies, by understanding the impact of the externalities of photovoltaic solar generation in different perspectives, both from consumers, the concessionaire and society.

It is noteworthy that, in this study, PV systems installed in the form of distribution generation by the electricity consumers themselves were considered. Other approaches are possible, such as considering the PV systems owned by the electric utilities. Finally, as future research work, we suggest: (i) seek new externalities and reassess the value of this new set of externalities; (ii) evaluate new perspectives for installing PV devices, such as larger systems, i.e. power plants above $5 \mathrm{MWp}$ and (iii) evaluate shared generation PV systems such as cooperative and condominium use.

Acknowledgments. This study was financed in part by the Coordenação de Aperfeiçoamento de Pessoal de Nível Superior Brasil (CAPES) - Finance Code 001, and this work was financed by Companhia Energética de Minas Gerais (Cemig-D) and by the Research and Technological Development Program - R\&D regulated by ANEEL, within the scope of the project "D0638 Analysis of the Viability of Photovoltaic Energy in Brazil in the 
Face of the Regulatory Framework of the Generation Distributed in the Brazilian Electricity Sector - Aneel RN 482/12", coordinated by the Federal University of Viçosa in partnership with the Pontifical Catholic University of Minas Gerais.

\section{References}

1. M.M.V. Cantarero, Of renewable energy, energy democracy, and sustainable development: A roadmap to accelerate the energy transition in developing countries, Energy Res. Soc. Sci. 70, 101-716 (2020)

2. MME, Ministry of Mines and Energy, National Energy Balance. (2020)

3. H. Ding et al., Cost reduction or electricity penetration: Government R\&D-induced PV development and future policy schemes, Renew. Sustain. Energy Rev. 124, 109-752 (2020)

4. ANEEL, National Electric Energy Agency, Normative Resolution 482 (2012)

5. REN21, Renewables 2019 Global Status Report (2019)

6. L.E.V. Souza, A.M.G. Cavalcante, Concentrated solar power deployment in emerging economies: The cases of China and Brazil,Renew. Sustain. Energy Rev. 72, 1094-1103 (2017)

7. C. Lacchini, J.C. Santos, Photovoltaic energy generation in Brazil - Cost analysis using coal-fired power plants as comparison, Renew. Energy 52, 183-189 (2013)

8. R.A. Shayani, M.A.G. Oliveira, Externalities of power generation with conventional and renewable sources. in Proceedings of the IV Brazilian Congress on Energy Planning (2008)

9. V. Martinez-Sanchez, M.A. Kromann, T.F. Astrup, Life cycle costing of waste management systems: overview, calculation principles and case studies, Waste Manag. 36, 343-355 (2015)

10. V. Giudice et al., The monetary valuation of environmental externalities through the analysis of real estate prices, Sustainability 9, 229-239 (2017)

11. B.A. Jones, Measuring externalities of energy efficiency investments using subjective well-being data: The case of LED streetlights, Resource Energy Econ. 52, 18-32 (2018)

12. V. Martinez-Sanchez et al., Evaluation of externality costs in life-cycle optimization of municipal solid waste management systems, Environ. Sci. Technol. 51, 3119-3127 (2017)

13. Y.F. Nassar, K.R. Aissa, S.Y. Alsadi, Estimation of environmental damage costs from CO2e emissions in Libya and the revenue from carbon tax implementation, Low Carbon Econ. 8, 118-132 (2017)

14. J. Sun et al., Capacity planning and optimization for integrated energy system in industrial park considering environmental externalities, Renew. Energy 167, 56-65 (2021)

15. K.J. Kim, H. Lee, Y. Koo, Research on local acceptance cost of renewable energy in South Korea: A case study of photovoltaic and wind power projects, Energy Policy 144, $11684(2020)$

16. S. Myojo, H. Ohashi, Effects of consumer subsidies for renewable energy on industry growth and social welfare: The case of solar photovoltaic systems in Japan, J. Jpn. Int. Econ. 48, 55-67 (2018)

17. L.F. Paula, M. Pires, Crisis and prospects for the Brazilian economy, Adv. Stud. 31, 125-144 (2017)
18. G.A. Xavier, D.S. Thesis, Analysis of externalities of distributed photovoltaic generation in Brazil, Federal University of Vicosa (2015)

19. ANEEL, National Electric Energy Agency, Electricity losses in distribution (2019b)

20. G.D.P. Silva, M.J. Souza, Estimation of energy generation through a photovoltaic system: implications for a floating system in lake Bologna, Belem-Para,Br. J. Renew. Energies 6, 109-121 (2017)

21. N. Mahmud, A. Zahedi, M.S. Rahman, An event-triggered distributed coordinated voltage control strategy for large grid-tied PV system with battery energy storage.in Proceedings of Conference (AUPEC) (2017) pp. 13-22

22. M. Jamil, A.S. Anees, Optimal sizing and location of SPV (solar photovoltaic) based MLDG (multiple location distributed generator) in distribution system for loss reduction, voltage profile improvement with economical benefits, Energy 103, 231-239 (2016)

23. V. Vita, T. Alimardan, L. Ekonomou, The Impact of distributed generation in the distribution networks' voltage profile and energy losses.in Proceedings of European Modelling Symposium (2015) pp. 260-265

24. ANEEL, National Electric Energy Agency,Voltage level compliance indicators 2021-2-25 (2019c)

25. R. Castro, S. Faias, J. Esteves, The cost of electricity interruptions in Portugal: Valuing lost load by applying the production-function approach, Utilit. Policy 40, 48-57 (2016)

26. EUROSTAT, Electricity prices for non-household consumers (2019a)

27. EUROSTAT, Electricity prices for non-household consumers - bi-annual data (2019b)

28. E. Leahy, R.S.J. Tol, An estimate of the value of lost load for Ireland,Energy Policy 399, 1514-1520 (2011)

29. P. Linares, L. Rey, The costs of electricity interruptions in Spain. Are we sending the right signals?, Energy Policy 61, 751-760 (2013)

30. J. Reichl, M. Schmidthaler, F. Schneider, The value of supply security: the costs of power outages to Austrian households, firms and the public sector,Energy Econ. 36, 256-261 (2013)

31. L. Röpke, The development of renewable energies and supply security: a trade-off analysis,Energy Policy 61, 1011-1021 (2013)

32. T. Zachariadis, A. Poullikkas, The costs of power outages: a case study from Cyprus,Energy Policy 51, 630-641 (2012)

33. ANEEL, National Electric Energy Agency, Consumer's day: ANEEL's actions lead to improved electricity supply in the country in 2018 Brasilia. (2019d)

34. CANADIAN SOLAR, Solar panel $350 \mathrm{~W}$ half-cell Canadian Solar - CS3U-350P. (2019)

35. S. Ekici, M.A. Kopru, Investigation of PV system cable losses, Int. J. Renew. Energy Res. 7, 807-815 (2017)

36. H.I. Dag, M.S. Buker, Performance evaluation and degradation assessment of crystalline silicon based photovoltaic rooftop technologies under outdoor conditions, Renew. Energy 327-337 (2019)

37. M.J. Sorgato, MS. Thesis, Thermal performance of naturally ventilated single-family residential buildings, Federal University of Santa Catarina, 2009

38. P.C. Almeida, MS. Thesis, Influence of the installation of photovoltaic systems on the value of buildings, Federal University of Vicosa, 2017

39. Hyperdata, IPH 100 Cities - Properati Hyperdata Measurement Index (2018) 
40. ANEEL, National Electric Energy Agency,. Average rates by consumption class and regions. Brasília (2019a)

41. A. Michaelowa, I. Shishlov, D. Brescia, Evolution of international carbon markets: lessons for the Paris agreement, Clim. Change 10, 1-24 (2019)

42. M.L. Bell et al., The avoidable health effects of air pollution in three Latin American cities: Santiago, Sao Paulo, and Mexico City, Environ. Res. 100, 431-440 (2006)
43. V. Kapsalis, D. Karamanis, On the effect of roof added photovoltaics on building's energy demand, Energy Build. 108, 195-204 (2015)

44. W. Zhang, L. Lu, J. Peng, Evaluation of potential benefits of solar photovoltaic shadings in Hong Kong, Energy 137, 1152-1158 (2017)

45. Y. Qiu, Y.D. Wang, J. Wang, Soak up the sun: impact of solar energy systems on residential home values in Arizona, Energy Econ. 66, 328-336 (2017)

Cite this article as: Pedro Henrique Gonçalves Rigueira Pinheiro Castro, Delly Oliveira Filho, Olga Moraes Toledo, Joyce Correna Carlo, Antônia Sônia Alves Cardoso Diniz, Integrated analysis of photovoltaic system externalities in Brazil: public health expenditures, energy quality, architectural aspects and real estate value, Renew. Energy Environ. Sustain. 7, 13 (2022) 